04

\title{
Особенности взрывчатого разложения тетранитропентаэритрита при воздействии пучком электронов с взрывоэмиссионным катодом
}

\author{
( Б.П. Адуев, ${ }^{1}$ Г.М. Белокуров, ${ }^{1}$ А.Г. Кречетов, ${ }^{2}$ И.Ю. Лисков ${ }^{1}$ \\ ${ }^{1}$ Институт углехимии и химического материаловедения Федерального исследовательского центра угля и углехимии \\ Сибирского отделения РАН, \\ 650000 Кемерово, Россия \\ ${ }^{2}$ Кемеровский государственный университет, \\ 650043 Кемерово, Россия \\ e-mail: lesinko-iuxm@yandex.ru
}

(Поступило в Редакцию 7 июля 2016 г.)

В работе проведено сравнительное исследование критической плотности энергии взрывчатого разложения тетранитропентаэритрита при воздействии пучком ускорителя электронов ГИН-600 $(240 \mathrm{keV}, 20 \mathrm{~ns})$ с взрывоэмиссионным катодом в условиях воздействия на образцы совместно пучка электронов и металлической низкотемпературной диодной плазмы и пучка электронов без воздействия плазмы. Показано, что вклад плазмы в развитие процессов взрывчатого разложения заметен при вероятностях взрыва $P \leq 0.2$. При увеличении плотности энергии и вероятности взрыва $P \geq 0.5$ вклад плазмы в суммарную плотность энергии пучка составил не более $10 \%$.

DOI: 10.21883/JTF.2017.07.44671.1980

\section{Введение}

В настоящее время выполнено большое количество работ, например [1-9], в которых осуществлялось инициирование детонации тетранитропентаэритрита (тэна), относящегося к классу бризантных взрывчатых веществ (БВВ), при воздействии пучком ускорителя электронов со взрывоэмиссионным катодом. Как правило, во всех экспериментах электронный пучок выводится из вакуумного диода через открытое отверстие, поэтому не исключено воздействие на образец низкотемпературной металлической плазмы, выходящей из диода после пучка электронов. Это позволило некоторым экспериментаторам предположить, что инициирование взрыва образцов происходит не в результате воздействия электронного пучка, а из-за взрывного испарения образца металлической плазмой, вылетающей из вакуумного диода ускорителя [8]. В работе [9] приведен ряд экспериментальных данных, опровергающих эту точку зрения. Однако для окончательного ответа на вопрос полезно проведение экспериментов по измерению критической энергии взрывчатого разложения как при совместном действии плазмы и пучка электронов, так и с отсечкой плазмы. Это позволит выявить вклад диодной плазмы в инициирования БВВ.

В настоящей работе проведены эксперименты с прямым измерением критической энергии взрывчатого разложения прессованных таблеток тэна калориметрическим методом.

\section{Объекты исследования и методики эксперимента}

В настоящей работе исследовались образцы поликристаллов тэна, изготовленные методом прессования.
Использовался порошок тэна с узким гранулометрическим распределением с максимумом $\sim 1.5 \mu \mathrm{m}$. Образцы прессовались с помощью гидравлического пресса в центре медной пластины толщиной $1 \mathrm{~mm}$, в которой имелось отверстие $\varnothing 3 \mathrm{~mm}$. Пластина взвешивалась до и после прессования. Находилась масса образца, и по известным размерам $(\varnothing 3 \mathrm{~mm}, d=1 \mathrm{~mm})$ находилась плотность образцов. В экспериментах использовались образцы с плотностью $\rho=(1.73 \pm 0.2) \mathrm{g} / \mathrm{cm}^{3}$.

Конструкция вакуумного диода и экспериментальной камеры с образцом представлена на рис. 1.

Источником инициирования взрывчатого разложения тэна служит ускоритель электронов ГИН-600 на базе генератора импульсного напряжения, построенного по схеме Аркадьева-Маркса (ГИН). Генерация электронного пучка происходит в результате взрывной эмиссии при приложении к катоду импульса высокого напряжения. В качестве катода 3 использовалась трубка из нержавеющей стали $\varnothing 3 \mathrm{~mm}$. Анод 4 представляет собой стальную пластину с отверстием $\varnothing 2.5 \mathrm{~mm}$ для вывода пучка электронов. Расстояние между катодом и анодом составляло $3.5 \mathrm{~mm}$. Параметры пучка электронов: эффективная энергия электронов $E=240 \mathrm{keV}$, длительность импульса $20 \mathrm{~ns}$. Пластина 6 с образцом 5 устанавливалась в вакуумной камере 2 ускорителя электронов 1 на корпусе анода 4. На тыльную сторону устанавливали медную пластину-свидетель 7. Наличие детонации фиксировалось по изгибу и пробою отверстия в пластине-свидетеле 7. Изменение плотности энергии пучка, подводимой к образцу, проводилось путем варьирования расстояния между анодом и пластиной с образцом. Для изменения расстояния между образцом и анодом использовались регулировочные шайбы 8 . Вся конструкция устанавливалась на шпильках 9 и поджималась гайками 10. 


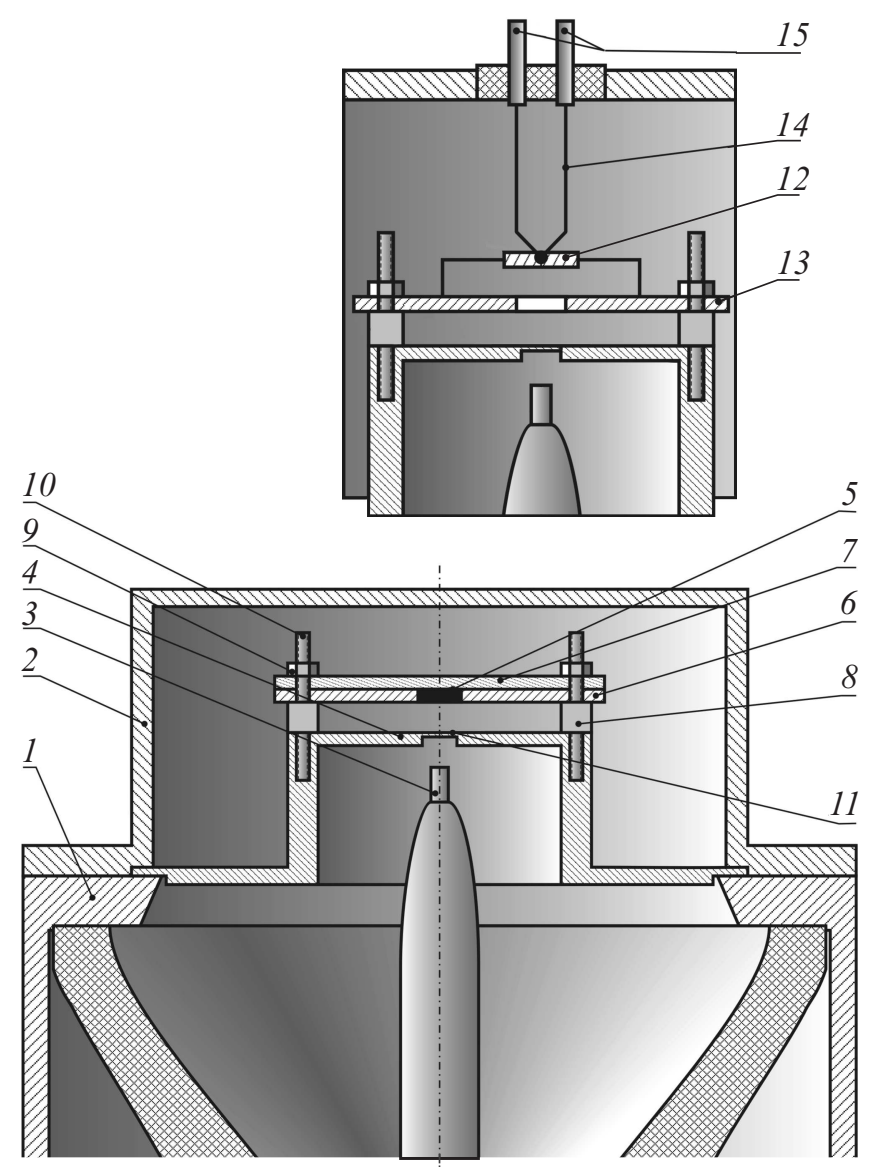

Рис. 1. 1 - ускоритель электронов, 2 - вакууная камера, 3 - катод, 4 - анод, 5 - образец (поликристалл тэна), 6 - медная пластина держатель, 7 - тыльная пластина, 8 - регулировочные шайбы, 9 - шпилька, $10-$ поджимная гайка, 11 - фольга, 12 - приемная пластина калориметра, 13 - коллиматор, 14 - термопара (медь-константан), 15 контактные выводы термопары.

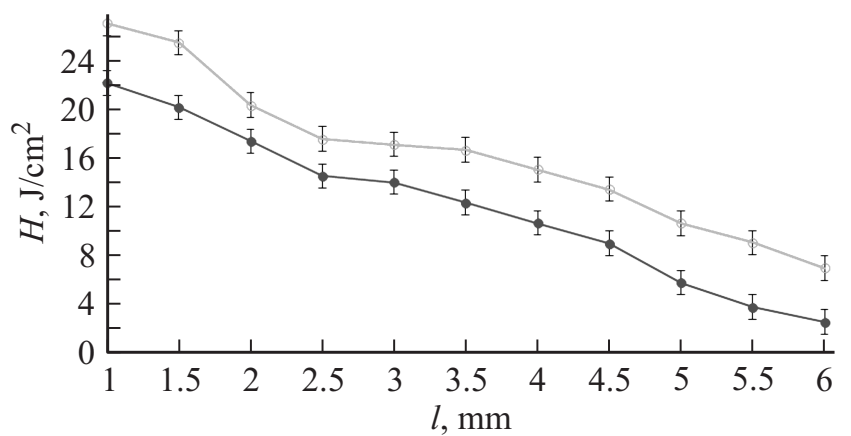

Рис. 2. Зависимость плотности энергии пучка ускорителя электронов от расстояния между анодом и образцом. • пучок электронов, о - пучок электронов совместно с металлической плазмой.

Для исследования воздействия пучка электронов металлическая плазма, выходящая из диода, отсекалась алюминиевой фольгой $14 \mu \mathrm{m}$, которая устанавливалась на отверстие анода 4.
Измерение плотности энергии, выводимой на образец, производилось калориметрическим методом. Конструкция представлена на рис. 1.

Над анодом вместо пластины с образцом устанавливалась стальная пластина 13 с отверстием $2 \mathrm{~mm}$, которая являлась коллиматором и могла, так же как и пластина с образцом, устанавливаться на различных расстояниях от анода с помощью регулировочных шайб 8 . За коллиматором устанавливалась приемная пластина 12 калориметра из меди размером $5 \times 5 \times 1 \mathrm{~mm}^{3}$, в которую впрессована дифференциальная термопара медь-константан 14. Сигнал с термопары через вакуумплотные контактные выводы 15 регистрировался гальванометром и определялась температура нагрева приемной пластины 12. Приемная пластина 12 крепилась к коллиматорной пластине 13 при помощи тонких стальных проволочек для уменьшения теплоотвода. Расстояние между пластиной 12 и коллиматором 13 составляло $1 \mathrm{~mm}$. При этом диаметр электронного пучка на превышал размера пластины 12 , что проверялось по отпечатку пучка на фотобумаге в месте расположения приемной пластины 12 .

При больших плотностях энергии на пластине 12 наблюдалось выжигание фрагмента за счет плавления в месте воздействия пучка. Потерю массы при плавлении учитывали взвешиванием пластины на аналитических весах до и после воздействия $n=10$ импульсов. При этом

$$
\Delta m=\frac{m-m^{\prime}}{10}
$$

где $m$ и $m^{\prime}$ - масса пластины до и после облучения соответственно.

Плотность энергии пучка с плазмой (или без плазмы), прошедшей через коллиматор 6 , равна сумме количества тепла, поглощенного пластиной 12 , и энергии, затраченной на вылет частиц с ее поверхности, деленной на площадь коллиматора:

$$
H=\frac{c m \Delta T+\Delta m\left(c\left(T_{\text {annell }}-T_{\text {romm }}\right)+\lambda\right)}{\pi r^{2}},
$$

где $c=0.38 \mathrm{~J} / \mathrm{g}$ - удельная теплоемкость меди, $m-$ масса приемной пластины, $\Delta T-$ показания гальванометра, $\Delta m$ - вылет массы приемной пластины за импульс, $T_{\text {annell }}=1356.6 \mathrm{~K}$ - температура плавления меди, $T_{\text {romm }}=293 \mathrm{~K}-$ комнатная температура, $\lambda=213 \mathrm{~J} / \mathrm{g}-$ удельная теплота плавления, $r$ - радиус отверстия коллиматора.

\section{Результаты и обсуждения}

Измерялась зависимость плотности энергии совместно пучка электронов и плазмы и отдельно пучка электронов с отсечением плазмы алюминиевой фольгой, прозрачной для электронов, в зависимости от расстояния от анода $1-6 \mathrm{~mm}$, с шагом $0.5 \mathrm{~mm}$. Соответствующие кривые представлены на рис. 2. На каждой точке делалось 10 импульсов и вычислялся доверительный 


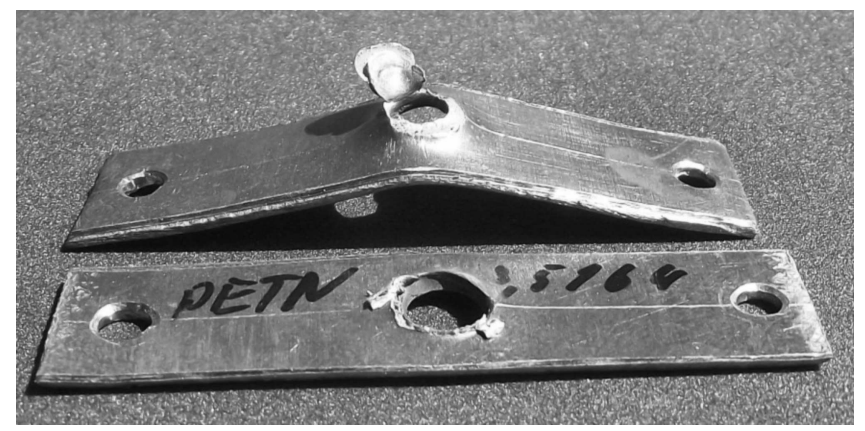

Рис. 3. Деформация подложки и пластины-свидетеля после взрыва.

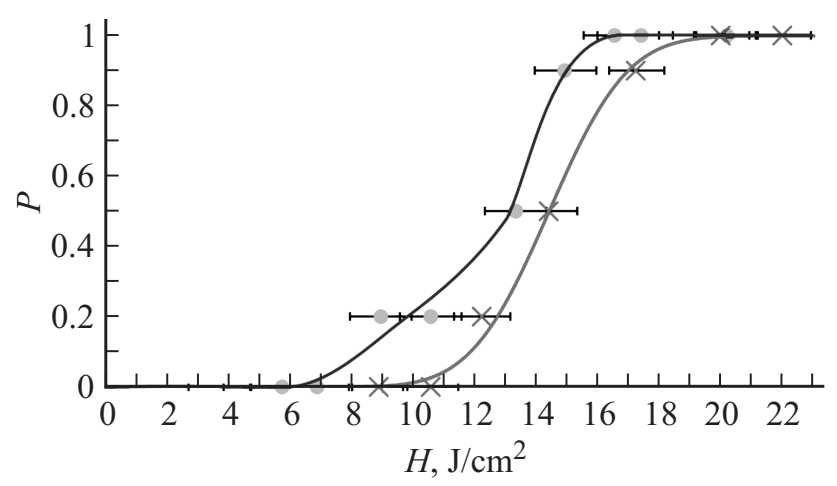

Рис. 4. Зависимость вероятности взрыва тэна от плотности энергии при инициировании поликристалла тена воздействием $\times$-пучка электронов и •-пучка электронов совместно с плазмой.

интервал по методу Стьюдента. Из калибровочных кривых виден заметный вклад металлической плазмы в общее количество тепла, поглощаемое калориметром. Следует отметить, что кривые на рис. 2 получены для заданной конфигурации вакуумного диода. При изменении, например, расстояния катод-анод, диаметра катода, отверстия в аноде и т.д. кривые рис. 2 будут иными и имеют смысл только для экспериментов, проведенных с использованной конфигурацией вакуумного диода.

В следующей серии экспериментов измерялась вероятность взрыва тэна в зависимости от плотности энергии, подводимой к образцу. Проведены две группы экспериментов: первая - при воздействии пучка электронов с отсечкой плазмы алюминиевой фольгой, вторая - при совместном действии электронного пучка и диодной плазмы. Регулирование плотности энергии производилось изменением расстояния между образцом и анодом. По известному расстоянию анод-образец и калибровочным кривым рис. 2 восстанавливалась плотность энергии, подводимая к образцу. На каждой заданной плотности энергии использовано по 10 образцов и определялась вероятность взрыва

$$
P=\frac{n}{10},
$$

где $n$ - число взорвавшихся образцов. За факт взрыва принимали разрушение пластины-свидетеля, в которой пробивалось отверстие, близкое к размерам образца (рис. 3). Кривые вероятности взрыва в зависимости от плотности энергии представлены на рис. 4.

При плотности энергии $H \leq 6 \mathrm{~J} / \mathrm{cm}^{2}$ видимых изменений с образцами не происходило. При увеличении плотности в интервале $H=7-11 \mathrm{~J} / \mathrm{cm}^{2}$ на образцах, подвергшихся только воздействию пучка электронов, наблюдалось разрушение поверхности либо распыление части таблетки. При совместном действии электронов и плазмы наблюдался взрыв с $P=0.2$. При этом остатков невзорвавшихся образцов в экспериментальной камере не наблюдалось. Отсюда можно сделать вывод, что в этом случае невзорвавшиеся образцы сгорали в результате нагрева поглощенной энергии плазмы. Таким образом, при совместном воздействии электронов и плазмы в диапазоне плотностей энергии $H=9-11 \mathrm{~J} / \mathrm{cm}^{2}$ наблюдается конкуренция процессов горения и взрыва. Критическая плотность энергии, соответствующая 50\% вероятности взрыва, составляет $H_{\mathrm{cr}}=14.5 \mathrm{~J} / \mathrm{cm}^{2}$ для пучка электронов и $H_{\mathrm{cr}}=13.5 \mathrm{~J} / \mathrm{cm}^{2}$ для совместного воздействия электронов и плазмы и близки в погрешности эксперимента. Во всяком случае, можно сделать вывод, что вклад плазмы в $H_{\text {cr }}$ составляет не более $10 \%$. При энергиях $H \geq 20 \mathrm{~J} / \mathrm{cm}^{2}$ вероятность взрыва $P=1$ для обоих случаев.

\section{Выводы}

1. При плотности энергии, когда вероятность взрыва не высока $(P \leq 0.2)$ при совместном воздействии пучка и плазмы, вклад плазмы в развитие химической реакции заметен. При этом наблюдается конкуренция взрывчатого разложения и горения образцов.

2. При вероятности взрывчатого разложения $1>P \geq 0.5$ совместное действие пучка электронов и диодной плазмы ведет к снижению критической энергии взрывчатого разложения менее, чем на $10 \%$ относительно воздействия на образцы электронного пучка без плазмы, что близко к погрешности измерений. Следовательно, развитие детонационного процесса в образцах обусловлено в основном воздействием пучка электронов, а вклад от воздействия металлической низкотемпературной плазмы незначителен.

\section{Список литературы}

[1] Корепанов В.И., Лисицын В.М., Олешко В.И., Ципилев В.П. // Письма в ЖТФ. 2003. Т. 29. Вып. 16. С. 23-28.

[2] Адуев Б.П., Белокуров Г.М., Гречин С.С., Тупицин Е.В. // Письма в ЖТФ. 2004. Т. 30. Вып. 15. С. 91-95.

[3] Адуев Б.П., Белокуров Г.М., Гречин С.С., Швайко В.Н. // Известия вузов. Физика. 2007. Т. 50. Вып. 2. С. 3-9.

[4] Адуев Б.П., Белокуров Г.М., Гречин С.С., Пузынин А.В. // Изв. вузов. Физика. 2008. Т. 51. Вып. 11/2. С. 104-106.

[5] Адуев Б.П., Белокуров Г.М., Гречин С.С. // Изв. вузов. Физика. 2009. Т. 52. Вып. 8/2. С. 249-252. 
[6] Адуев Б.П., Белокуров Г.М., Гречин С.С., Пузынин А.В. // Химическая физика. 2010. Т. 29. Вып. 6. С. 54-57.

[7] Олешко В.И., Лисицын В.М., Скрипин А.С., Ципилев В.П. // Письма в ЖТФ. 2012. Т. 38. Вып. 9. С. 37-43.

[8] Морозов В.А., Савенков Г.Г., Брагин В.А., Кач, В.М., Лукин А.А. // ЖТФ. 2012. Т. 82. Вып. 5. С. 129-134.

[9] Адуев Б.П., Белокуров Г.М., Гречин С.С., Лисков И.Ю. // ЖТФ. 2014. Т. 84. Вып. 1. С. 61-66. 